\begin{tabular}{|llllll}
\hline Motrivivência & Ano XX, & No 30, P. & 09-27 & Jun./2008 \\
\hline
\end{tabular}

\title{
As Antinomias Dialéticas do Lazer
}

\author{
The Dialectical Antinomies for Leisure
}

Gustavo Martins Piccolo'

\begin{abstract}
Resumo Abstract
O presente texto busca, através de um árido processo de revisão de literatura, demarcar o lazer como espaço dialético de apropriação, fruição e objetivação cultural pela vivência do lúdico na sociedade, acentuando ao fenômeno lazer a característica de ferramenta mediativa na produção do conhecimento, cuja materialidade pode estar tanto em consonância à incorporação dos objetivos propostos pelas classes dominantes como também no sentido de crítica a estes postulados. Ainda no arcabouço do texto assinalamos possíveis relações entre a Educação Física e o lazer, as quais objetivam a produção de um espaço lúdico libertário e emancipatório.

The article looks, through a dry process of literature review, demarcate the leisure at the space dialectic of ownership, enjoyment and cultural objectification by the experience of entertainment in society, stressing the leisure phenomenon characteristic of mediated tools in the production of knowledge, which materiality can either be in line to the incorporation of the goals proposed by the hegemonic classes but also to critique these assumptions. Still in the framework of the text pointed possible relationships between physical education and leisure, which aim to produce a play area libertarian and emancipated.
\end{abstract} Palavras Chaves: Lazer; Educação Física; Cultura.
Keywords: Leisure; Physical Education; Culture.

1 Doutorando em Educação Especial pela UFSCar e professor efetivo de Educação Física da Rede Estadual de Educação do Estado de São Paulo, município de Araraquara. 


\section{Introdução}

A demarcação de antinomias em um fenômeno multifacetado, complexo e polissêmico como o lazer exige a concomitante viagem histórica ao próprio processo de constituição de seu campo de estudos, por isso, ordena inequivocamente um repensar epistemológico sobre a arquitetura de seu campo. Claro está que esta é uma tarefa essencialmente teórica, apesar de não esquivar-se do solo da prática, na medida em que sua realização impõe a objetivação de uma árida empreitada rumo ao escrutínio dos autores que se valeram do lazer como objeto de pesquisa. A lógica desse processo demandaria um tempo e espaço rigorosamente amplos para que as principais concepções sobre aquilo que podemos denominar de cultura vivenciada e fruída no tempo lúdico perpassasse por um processo exegético sincrônico. Como não temos nem tempo, tampouco espaço e calibre teórico para uma reflexão de tal monta, neste artigo nos deteremos principalmente sobre as antinomias presentes nas produções nacionais sobre o lazer enquanto prática social e seu impacto no que tange a produção do conhecimento.

O único teórico não brasileiro enfocado, ainda que de maneira subliminar, será Jofre Dumazedier, cuja importância e envergadura das análises no campo do lazer influenciaram direta ou indiretamente quase que toda a geração de estudiosos brasileiros sobre dito fenômeno. Com isso, não estamos enfatizando, em hipótese alguma, uma concordância entre este estudo e as principais idéias colocadas por Dumazedier (1976, 1980, 1994, 1999), aliás, na grande maioria das vezes, nossa linha de análise seguirá o caminho oposto ao assumido pelo autor, mas apenas enfatizando a importância e, diríamos mais, relevância que alguns apontamentos frutiferamente demarcados pelo autor francês ainda exerce sobre as idéias arquitetadas acerca do fenômeno lazer, seja para a crítica ou afirmação de seus pressupostos.

Dito isto, intuímos com este texto demarcar as principais contradições que ainda povoam os estudos sobre o lazer em nosso país, lançando possíveis novos olhares sobre questões basilares à compreensão do referido fenômeno, tais como a origem histórica do lazer, a concepção irrestrita do lazer como vivência de cultura e espaço de crítica aos mecanismos de conformação social, a transformação do lúdico em mercadoria, dentre outras problemáticas cardeais ao lazer, as quais, quando pensadas dialeticamente, inequivocamente nos colocam a necessidade de pensarmos os conceitos 
em estado de devir e movimento contínuo, cuja apreensão tange o objetivo deste texto. Com isso, além de realizar uma reflexão sobre o lazer estaremos certamente contribuindo para um novo pensar sobre a produção do conhecimento a partir de tal fenômeno, seja quando pensamos na importância que o conhecimento assume para a arquitetura de uma experiência prática ou quando a experiência prática funda os alicerces para a produção de novos conhecimentos.

\section{Caminhos históricos do lazer}

Certamente quando pensamos em demarcar os possíveis caminhados históricos trilhados pelo lazer o primeiro passo reside em historicizarmos sua gênese, ou seja, refutar qualquer argumento fundado em uma suposta atemporalidade do lazer. Assim, discordamos radicalmente das posições que demarcam o lazer como uma atividade existente desde as primievas formas de sociabilidade. O lazer é um fenômeno historicamente construído, e como tudo o que é histórico tem sua data de nascimento, consubstanciada a partir da Revolução Industrial Inglesa. Desde essa época, o trabalho realizado socialmente se distingue de todas as outras atividades realizadas nas esferas cotidianas, diferenciação que se estende a criação de um espaço específico para o labor, sendo que neste ponto o público e o privado começam a efetivamente se separar. Marcellino $(2000,2001)$ e Marcassa (2002) tecem importantes considerações sobre este processo de gestação histórico-cultural do lazer. Para Marcellino (2000) o lazer é produto da Revolução Industrial Inglesa, principalmente a segunda (caracterizada pela formação de um mercado mundial, além de diversos inventos relacionados ao transporte e a telecomunicação, os quais em conjunto fortaleceram o movimento urbanizador), da divisão do trabalho, da alienação dos homens frente aos produtos por eles criado, das reivindicações do operariado por um maior tempo de não trabalho e, acrescentemos, também da busca incessante dos capitalistas em combater o ócio. Destarte, foi a maior produção material alavancada pelas novas técnicas industriais conjuntamente a abertura de um tempo de não trabalho que propiciou o ambiente adequado ao aparecimento do fenômeno por nós denominado de lazer, mesmo considerando que sua protoforma estivesse relacionada a aspectos funcionalistas, principalmente no que tange a recuperação das forças físicas para o trabalho, ou seja, basicamente ao descanso e a incorporação incondicional aos ditames estruturais da sociedade. 
Ou seja, a burguesia tencionava que o lazer atuasse reflexivamente como uma mediação de segunda ordem a incorporação dos ritos e ritmos capitalista, portanto, uma mediação em consonância ao projeto alienante da classe capitalista ainda em gestação.

Nesse sentido faz-se de fundamental importância recuperar alguns apontamentos destacados por Marcassa (2002). Para a referida autora, o modus de vida social anterior ao capitalismo industrializado estava inextricavelmente ligado à natureza, sendo que em seu interstício trabalho e diversão coexistiam em uma unidade temporal indefinida. Unidade temporal que pode ser definida mediante múltiplos olhares e/ou perspectivas, quais sejam: natural, cíclica, mística, religiosa, vetorial, mecânica, psicológica, etc. Estes múltiplos tempos foram vivenciados de distintas maneiras ao longo da história das culturas e épocas societais. Em toda a Antiguidade as principais atividades (agricultura, festas, acasalamento) eram guiadas pelo tempo da natureza, ou melhor, pelo movimento ascendente e descendente do sol e lua.

Nessa época, nas palavras de Rolim (1989, p.44) "o sentimento do tempo é limitado em sua extensão, pois se estende apenas ao futuro mais próximo e ao passado mais recente", é o ineliminável tempo do presente, do aqui e agora. De acordo com Gebara (1994, 1997), mesmo no medievo não se rompe radicalmente com essa noção de tempo, cuja materialidade apenas se consubstanciará com o desenvolvimento do capitalismo industrial e do modo de produção burguesa, os quais generalizam o controle, a regularidade e universalidade da medição do tempo, desde já, o tempo do relógio. Essa nova forma de ver e viver o tempo produz implicações decisivas nas próprias relações sociais estabelecidas nas esferas cotidianas e não cotidianas, pois engendra a perda de domínio do homem sobre seu tempo, não mais relacionado ao seu saber fazer e sua condição física. Nesta intersecção histórica enquanto o tempo é ditado pelo relógio, o ritmo humano é alinhavado pelas máquinas. Tal ritmo efetivamente configura as relações sociais no trabaIho dos mais distintos seres humanos, independentemente de sua idade, gênero ou força física, estabelecendo pela primeira na história uma divisão ontológica entre o tempo humano, a citar: o tempo do trabalho e do não trabalho ('tempo livre').

Assim, o tempo livre e o tempo de trabalho passam a ganhar contornos bem definidos, aliás, quase que demarcatórios, derivando ao primeiro o processo de produção 
e reprodução da existência e ao segundo a realização de atividades não diretamente relacionadas ao trabalho. Coerentemente, o lazer é por excelência a forma dominante de apropriação do tempo livre ${ }^{2}$ nas sociedades capitalistas contemporâneas, cuja materialidade representa um complexo conjunto de intersecções entre as esferas econômicas, políticas, sociais e culturais engendradas pela égide do capital. O processo responsável por esse desenrolar está estritamente relacionado com a quebra radical do tempo natural do trabalho em tempo rigidamente cronometrado, imposto pela industrialização mercantil praticada no capitalismo. Essa passagem de um tempo ao outro implicou uma verdadeira revolução no desenrolar das relações sociais, sendo que, desde então, o tempo de trabalho calculado pelo relógio e pela máquina passa a efetivamente ser um inimigo inconciliável a prática do ócio nesta esfera. Aliás, o ócio passa a ser visto pelos burgueses como uma verdadeira mazela social, produtora de vícios e deturpações que prejudicavam a produção capitalista. Também na crítica ao ócio é que podemos notar o aparecimento do lazer, o qual surge como um palco de reivindicações trabalhistas, mas também como campo de ação projetiva dos próprios burgueses, ou seja, em seu nascedouro, o lazer está em íntima coerência aos postulados da sociedade industrial. Por isso, de acordo com Mascarenhas (2005, p.231) "o lazer se afirma na própria dinâmica de hostilidade do capitalismo ao ócio. Dentro de uma racionalidade e funcionalidade que se renova, o lazer é hegemonicamente subserviente e útil às exigências e necessidades do capital".

Apenas ao escrutinar este universo histórico podemos compreender o fenômeno do lazer, produto de transformações societais alavancadas por diferentes relações entre o homem e seu meio natural/social, mais especificamente a passagem do modo de produção feudal para o capitalista industrializado, fato este que nos permite criticar pela raiz a suposta atemporalidade do lazer na sociedade ou sua suposta sinonímia

2 Claro está que o lazer não compreende a totalidade das atividades realizadas neste tempo de não trabalho, já que diversas outras atividades fazem parte deste universo, tais como as obrigações familiares, a igreja, a escola, atividades estas que não podem ser confundidas com o lazer propriamente dito. Assim, nas palavras de Marcassa (2002), é importante destacar o tempo do lazer na intersecção entre o tempo livre do trabalho e a exclusão de outras atividades anteriormente citadas, denominando-o, para empregar um termo de Mascarenhas (2005), de tempo livre das necessidades. 
com o ócio ${ }^{3,}$ tão reiterada por autores como De Masi (2000).

Destarte é completamente errônea a idéia de que o lazer alcança seu apogeu atitudinal quando se aproxima do antigo ideal grego de ócio, entendendo este como a atividade lúdico-estética desvinculadas a quaisquer preocupações ou necessidades existenciais, ou seja, aquela atividade dedicada em sua completude ao desenvolvimento físico, ético e intelectual dos sujeitos. Tão ou mais equivocada é a idéia expressa por De Masi (2000) de que hodiernamente estamos presenciando o fim da sociedade do trabalho e o principiar da sociedade do tempo livre, fundamental a prática do lazer propriamente dito, na medida em que essa posição desconsidera todos os condicionantes da diminuição do tempo de trabalho e do desenrolar da vida nas sociedades capitalistas. Neste momento cabe citar as palavras de Lessa (1996, p.20) para compreendermos mais detidamente a magnitude e os conflitos envoltos pela suposta diminuição da jornada de trabalho e o aumento do tempo livre no capitalismo. Passemos a elas:

Nos dias em que vivemos, um exemplo desse fato possibilidade de maximização do tempo livre) é a introdução da automação e da informática na produção. É hoje inegável o quanto isso poderia significar no sentido de diminuir a jornada de trabalho efetivamente necessária para a reprodução da sociedade, aumentando assim o tempo livre dos indivíduos. A esfera das necessidades poderia consumir um tempo de trabalho da humanidade infinitamente menor ao que se absorve hoje, e a esfera da liberdade poderia ser ampliada de modo significativo. O que isso significaria no sentido da emancipação humana é

3 A noção clássica de ócio, intimamente ligada ao estado de não sujeição às obrigações existenciais, carrega consigo o total desprezo das práticas materiais, que são vistas como entraves ao livre desenvolvimento do indivíduo, mais do que isso, são interpretadas como atividades menores em relação às atividades criadoras e contemplativas, estas sim, verdadeiras fontes de desenvolvimento. Assim, a noção de ócio dos gregos pressupõe como ponto de partida a divisão classista do trabalho e a exploração de muitos por poucos, ou seja, está em total consonância com um modelo aristocrático e discriminatório de sociabilidade. Nunca é demais lembrar que o ócio na Grécia antiga era privilégio de uma pequena parcela de pessoas, os proprietários, sendo que a vida no ócio nada tinha a ver com a apropriação do tempo livre, pois como demonstra Hobsbawn (1991), não poderia haver apropriação do tempo livre para quem não se relacionava ao tempo de trabalho. O ócio grego era fundado sob o escravismo e o trabalho de muitos para poucos, logo, admitir essa possibilidade de ócio significa também trazer como forma de existência um regime sequaz na sua capacidade discriminatória e não promover a universalidade do gênero humano como salienta De Masi (2000). 
por si evidente. No entanto, enquanto medição para potencializar a extração da mais-valia, a automação e a informática nada mais significam senão desemprego, miséria e agravamento das desigualdades sociais. E, nesse quadro histórico, quanto mais elas potencializarem a produtividade do trabalho, mais miséria produzirão. O capital, portanto, de impulsionador revolucionário da humanidade entre os séculos XIII e XVIII, se converteu em um obstáculo cada vez mais formidável, conforme avança o tempo, à plena explicitação categorial do gênero humano.

$\mathrm{Na}$ complexa conjuntura destes elementos, concluímos que o lazer se trata de um fenômeno tipicamente moderno, perpassado por relações de hegemonia com as esferas do trabalho, do tempo, do lúdico vivenciado, do espaço disponibilizado e até do ócio criticado. Por todas essas relações, como bem pontua Marcassa (2002), o lazer se configura como uma espécie de instituição com um arcabouço de práticas e normas que lhe confere um estatuto específico e próprio. Neste estatuto está implícita a prática de atividades corporais e lúdicas dos mais diversos tipos, seja para o relaxamento, diversão, desenvolvimento físico, cultural e gnosiológico ou até mesmo para a alienação, da qual o lazer não pode fugir. Logo, não há como compreender a globalidade do fenômeno lazer deslocado do contexto moderno, independentemente do produto gerado pelo lazer, seja em direção à emancipação ou a conformação à realidade circunscrita pelo capitalismo.

Estes apontamentos desmistificam o lazer como prática social essencialmente libertária e emancipatória, posto que a experiência por ele proporcionada deveria, ao menos em tese (e esta é uma tese unilinear e burguesa) servir como ferramenta mediativa a criação de uma consciência ingênua, porém, divertida, no operariado. Essa tendência também é observada, guardada as devidas proporções e com algum atraso temporal, no contexto brasileiro, explicitado a seguir.

\section{O lazer no Brasil}

De acordo com Marcassa (2002), a invenção do lazer em nosso país está ligada ao processo de internacionalização do capital entre os últimos decênios do século XIX e as primeiras décadas do século $X X$. É nesse momento que se dá, em nosso país, a supressão do trabalho compulsório, a abertura de exploração mercadológica do tempo livre e a urbanização das cidades, marca fundante da prática do lazer e do rompimento da condição temporal 
já citada anteriormente. Aqui, o ócio também já começa a ser controlado com grande efetividade, intuindo ajustar o modus de vida social as exigências do sistema capitalista, resumindo, já é possível notar uma ação deliberada de, mediante atividades lúdicas, amoldar a subjetividade do operariado aos postulados e interesses do capital, cuja marca característica é a submissão do homem ao processo de trabalho, aquilo que Marx (1971) corretamente chamou de prevalência do trabalho morto sobre o trabalho vivo.

Nesse sentido, Marcassa (2002) ressalta que as atividades lúdicas e a prática do descanso passam a ser codificadas pela racionalidade do mercado de trabalho. Apenas executo aquilo que não prejudica meu labor, essa talvez seja a máxima do lazer em seu nascedouro. Por isso, não há como negar o fato de o lazer haver ressignificado o próprio conceito de ócio mediante a criação do tempo livre em oposição ao tempo de trabalho. De acordo com Marcassa (2002, p.92-93)

É preciso perceber ainda o tempo livre como uma forma de vida típica do capitalismo, em que trabalho e tempo livre na aparência são opostos, mas na verdade formam um binômio indissociável. O tempo livre torna-se a extensão da própria lógica de produção, ou seja, hegemonicamente, ele se curva ao capital.

Os estudos sobre o lazer no Brasil começam a se consolidar efetivamente a partir da década de $70^{4}$ do recém terminado século, cujos reflexos se materializam na criação de grupos de pesquisa envoltos da referida temática, na elaboração de livros, congressos, teses e a veiculação do lazer nas mais diversas mídias. A presente data tem como marco significativo o congresso intitulado "Seminário sobre lazer: perspectiva para uma cidade que trabalha", realizado em São Paulo sob a organização do SESC. Desde então, de acordo com Requixa (1980, p.95) "[...] a própria palavra lazer passou a fazer parte do vocabulário dos profissionais da área do social e integrou-se, com destaque, no vocabulário da imprensa". Além de tal evento cabe também ressaltar que outro elemento que possibilita destacar a década de 70 do século $X X$ como

4. É importante ressaltar neste momento que a década de 70 representa o marco da difusão dos estudos sobre o lazer. Por isso, não podemos esquecer que, desde 1962, a disciplina recreação, sempre em estrita relação ao lazer, já era oferecida nos cursos de Educação mediante o Parecer n. 298, publicado em 17/11/1962 pelo Conselho Federal de Educação. 
estopim dos estudos sobre o lazer no Brasil estar relacionado à divulgação, também nesse período, das primeiras obras de Dumazedier, principalmente de sua Sociologia Empírica do Lazer (1999).

É importante ressaltar aqui que o SESC, conjuntamente ao SESI, exerceu importante papel na divulgação do lazer e na sua conformação aos interesses do Estado, intuindo, nas palavras de Sant'Anna (1994, p.49) munir "o trabalhador em seu tempo livre dos valores necessários ao aumento da produtividade e ao cultivo de uma sociedade integrada, na qual os conflitos são sublimados em favor do espírito comunitário que se ambicionava criar". Iniciativa similar quanto à propagação do lazer com fins organicamente ideológicos encontrase no movimento conhecido em nosso país como EPT (Esporte para Todos), que objetivava, a partir do lazer consubstanciado por práticas esportivas, desenvolver a importância e prevalência da competição sobre outros comportamentos sociais, enfatizando reiteradamente valores como a família, a saúde e o patriotismo. Devido a todos estes elementos é quase inegável o papel desempenhado pelo lazer como esteira aos interesses do capital, por isso, engana-se quem pensa que o lazer tenha nascido como alvo de crítica a burguesia, muito pelo contrário, pois buscava exatamente a afirmação inquestionável desses interesses. Este forte viés ideológico característico da década de 70 fez com que o lazer fosse entendido principalmente a partir de seu caráter alegre, divertido, compensador e disciplinador, ou seja, como um mecanismo de recomposição da força necessária ao trabalho e reprodução do capital. Entretanto, como todo fenômeno social o é essencialmente dialético, o lazer também carrega em seu bojo a possibilidade de crítica ao sistema que lhe dá sustentação e o compõe, na medida em que ao facilitar a apropriação dos principais interesses capitalistas também pode gerar sua compreensão mais detalhada e caminhos para sua superação.

Esta percepção vem a tona a partir da década de 80 do século $\mathrm{XX}$, muito influenciada pelo contexto singular em que vivia o Brasil naquela época, marcada pela abertura política e também pela imersão de um viés mais crítico da Educação Física em nosso país. A visão mais crítica do lazer emerge no cenário acadêmico a partir do estudo de Faleiros (1980), que questiona o caráter funcionalista das posições de Dumazedier (1980, 1999), e das contribuições de Marcellino (2000, 2001, 2002, 2003), que, ancorado em pressupostos gramscianos, destaca o lazer a partir da inter-relação 
entre as variáveis atitude e tempo. Apenas a partir desse momento começa em nosso país uma crítica a posição de Dumazedier (1999, p.34), e de sua famosa conceituação do lazer como representando o "conjunto de ocupações às quais o indivíduo pode entregar-se de livre vontade, seja para repousar, seja para divertir-se, recrear-se e entreter-se, ou ainda para desenvolver sua formação desinteressada, [...] após livrar-se das obrigações profissionais, familiares e sociais".

A crítica a definição de Dumazedier (1999) sobre o lazer alavanca inequivocamente o debruçar de estudiosos brasileiros para a criação de um novo conceito de lazer, o qual deveria surgir necessariamente da contestação das concepções subjetivistas do lazer, que o encarava apenas no sentido de uma atividade prazerosa, descompromissada e desinteressada e também se descolar da vertente funcionalista de lazer, tão cara aos estudos de Dumazedier (1999). A dificuldade complexidade deste objetivo fez com que Marcellino $(2001,2002)$ ressalte a inexistência de um consenso teórico a respeito do que afinal seja o lazer, embora reconheça a urgência no trabalho conceitual com essa definição, pois as categorias não são apenas recursos lingüísticos, uma vez que moldam práticas e ações sobre estas atividades, enfim, são experiências teóricas que medeiam à prática, produzindo diversas formas de conhecimento ou pistas a sua construção. Devido a estes elementos faz-se de fundamental importância apresentar algumas definições sobre o lazer como fenômeno histórico.

\section{Conceitos e preceitos: o lazer e as reflexões dele advindas}

Bramante (1998) destaca que o lazer traduz uma dimensão privilegiada de expressão humana mediante a atividade lúdica. $\mathrm{Na}$ visão do referido autor, o lazer é configurado pela peculiaridade de representar uma esfera orgânica a prática da liberdade, cujo principal vetor está direcionado a diversão e alegria. Destarte, Bramante (1998) não se distancia muito da concepção de Dumazedier, aliás, acaba sendo caudatário do funcionalismo. Funcionalismo que, nas palavras de Padilha (2003) vê o lazer como algo necessariamente bom, enquanto o trabalho representa sua antítese, sendo assim, a esfera do lazer é encarada pelo funcionalismo como uma válvula de escape para o não enfrentamento dos problemas e mazelas sociais, posição claramente conservadora e reacionária. Ou seja, o lazer é visto como mais um dos mecanismos reguladores do equilíbrio 
social. Um esboço de crítica a esta concepção de lazer é apresentado por Marcellino (2001).

Para Marcellino (2001, 2002, 2003) o lazer pode ser entendido como cultura vivenciada no tempo disponível. Disponível porque liberado das obrigações profissionais, sociais, familiares, religiosas e domésticas, sendo neste tempo que os homens podem praticar o lazer em sua plenitude. Assim, o lazer não mais é visto apenas como sinônimo de divertimento ou descanso, pois é um elemento crucial ao desenvolvimento ontogênico, na medida em que estreita e alarga simultaneamente os vínculos dos indivíduos com a sociedade. Nas palavras de Marcellino (2002, p.45-46), desde que corretamente mediado, o lazer pode se configurar como uma

[...] atividade não conformista, mas crítica e criativa de sujeitos historicamente situados. Assim, a vivência do lúdico precisa ser considerada também na sua contribuição para que os níveis culturais conformistas sejam superados e que a prática de atividades de lazer se transforme em participação efetiva. Entendo, ainda, a participação cultural como uma das bases para a renovação democrática e humanista da cultura e da sociedade, na perspectiva gramsciana, tendo em vista, não só a instauração de uma nova ordem social, mas de uma nova cultura, iniciada pela necessária reforma intelectual e moral. Isso não significa o isolamento do plano cultural, do social e do econômico, mas tão-somente, que não cabe justificar o imobilismo pela existência de uma ordem social adversa. Pelo contrário, essa situação aumenta a responsabilidade de atuação na vida cultural, procurando um vínculo orgânico com o povo, buscando sua participação cultural efetiva.

Com base nestes pressupostos Marcellino (2002) destaca o aspecto educativo do lazer, desde que este seja entendido como um dos possíveis canais de atuação no plano cultural, intuindo objetivar novas formas de sociabilidade, pois apenas assim o lazer se transforma em instrumento de contra-hegemonia e de crítica a miséria e opressão que abundam as múltiplas esferas da sociedade capitalista, por conseguinte, o lazer também pode adquirir uma função de elevação de nossas consciências para além do senso comum, fato de fundamental importância para traçarmos caminhos sociais mais fraternos e solidários.

No entanto, a prevalência do lazer apenas como atividade materializada no tempo disponível das obrigações sociais, acaba por 
afastar uma possibilidade frutífera de contato entre a Educação Física e o lazer, pois uma vez que a Educação Física faz parte de um conjunto obrigatório de disciplinas escolares das quais o aluno não pode fugir, além do controle temporal, institucional e atitudinal pelas palavras e objetivos docentes estabelecidas pela disciplina, claramente o lazer acaba por ganhar espaço apenas fora deste ambiente. Ou seja, quando Marcellino (2002) fala em educação para o lazer está pensando fundamentalmente na educação não escolar, posição da qual discordamos frontalmente. Não que desconsideramos a importância do tempo livre de obrigações para o lazer ou da educação assistemática para a formação da personalidade humana, mas, sim, que acreditamos no potencial relacional dialético entre Educação Física e lazer no que tange a diversificação e problematização das atividades lúdicas realizadas cotidianamente. Assim, acreditamos que a Educação Física mediante seus esportes, jogos e brincadeiras pode gerar uma ação reflexiva produtora de novos conhecimentos e vivências práticas do lazer, funcionando, por conseguinte, como elo mediador a prática de um lazer como campo de relações sociais que transcenda a esfera do em si para os domínios humano-genéricos, humanizando a prática, a qual redimensionará e engendrará a produção de novos conhecimentos em um ciclo de recomposição antitético por superação de conhecimentos interminável. Destarte, inexiste oposição cartesiana entre lazer e Educação Física, principalmente quando pensamos na prática como produtora de teoria e vice-versa.

Ainda no que tange a concepção sobre o lazer, merece destaque as posições de Marcassa (2002) e Mascarenhas (2005). Para Marcassa (2002), o lazer deve ser considerado como uma instituição que se funda na tensão entre interesses antagônicos, compreendido não como cultura vivenciada no tempo disponível (posição defendida por Marcellino), mas, sim, como tempo e espaço de organização da cultura, cuja principal finalidade reside na possibilidade de fornecer um ethos de criação estético-lúdica para a população, estimulando, assim, a autonomia em dirigir nossas escolhas.

Mascarenhas $(2001,2005)$ tem seu ponto de partida ancorado em concepções similares àquelas edificadas por Marcassa (2002), sendo que para o referido autor, o lazer deve se transformar em um mecanismo de resistência à dominação ideológica, objetivando a criação de uma nova sociedade. Em suas palavras (2005, p.01) o lazer deve atuar 
[...] como força de reorganização da sociedade, agência educativa capaz de fomentar e colaborar para a construção de novas normas, condutas e valores para o convívio entre os homens [...] enfim, deve expressar autenticamente a realidade na qual está inserido. Neste contexto, o lazer passa a ser entendido como tempo e lugar da construção de cidadania e exercício da liberdade.

Em síntese, excetuando a conceituação de Bramante (1998), não acreditamos haver uma contraposição frontal entre Marcellino (2000, 2001, 2002), Marcassa (2002) e Mascarenhas (2001, 2005), principalmente os dois últimos autores, que trabalham sob princípios sincrônicos de entendimento da sociedade, cultura e do lazer. Estas concepções apresentadas dão um painel geral de como podemos entender analiticamente o lazer, embora é importante frisar que essas concepções são produtos históricos, logo, a história que as validou também pode em algum dia exercer efeito oposto. Dito isto, é extremamente difícil conceituar com rigor epistemológico o que seja lazer, mas não nos furtamos a essa tentativa.

Consideramos o lazer como uma atividade conformista e criativa em relação à realidade, destarte, pode exercer tanto a função de transformação social (conjuntamente a outros elementos) como de interiorização dos processos alienantes demarcatórios das relações de produção capitalistas. Lazer que possui sua temporalidade específica definida de forma dialética e não cartesiana, atuando em diálogo sincrônico/diacrônico com a cultura da qual faz parte, configurando-se tanto como elemento de sua reprodução, como também de sua organização, produção e fruição. A via do lúdico constitui-se como seu traço demarcatório, mas nem sempre este se funda como atividade desinteressada, principalmente quando enxergamos no lazer uma ferramenta de crítica projetiva à sociedade. Assim, o lazer é tecido entre todas suas partes constituintes por um novelo dialético que o transforma em uma atividade instrumentalizada e instrumentalizável. É tanto necessidade como liberdade, alienação ${ }^{5}$ e emancipação, reprodução e produção do conhecimento,

5 Nesse sentido as práticas mais nocivas aos indivíduos, dependendo de sua temporalidade e da relação que os sujeitos estabelecem com ela, também podem ser consideradas como lazer, tais como os jogos de azar, o consumo de drogas lícitas e ilícitas, as brigas com horas marcadas pela internet. Assim, embora discordemos frontalmente de sua existência não podemos negá-las, na medida em que são vivenciadas cotidianamente na sociedade contemporânea. Mesmo que não desejamos estas práticas elas são vivenciadas por uma imensa gama de pessoas, inclusive fazendo parte da complexa teia de produção e consumo das mercadorias produzidas no capitalismo. 
mediação e ação propriamente dita, direta, mas não é tempo livre e tempo de trabalho alienado simultaneamente, ou seja, sua dialética não iguala os mais diversos fenômenos, posto que os coloquem em relação de antítese constituinte em que um pólo é superado por incorporação pelo outro na espiral dialética de produção do conhecimento humano e dos fenômenos sociais.

Essa dificuldade para se conceituar o lazer se acentua mais ainda, em nosso ponto de vista, quando consideramos as transformações sociais hodiernas derivadas do fim do Estado de bem-estar social, elemento marcante da vida em países americanos e europeus durante quase trinta anos, a crise de emprego, de salário, de valores e da própria estrutura do sistema capitalista. Certamente todos estes valores não passam incólume a formatação do lazer na sociedade contemporânea, a qual tudo transforma em mercadoria, inclusive, o próprio lazer. Esta nova realidade coloca de forma ainda mais sobressalente o caráter não necessariamente benéfico desempenhado pela prática do lazer na sociedade, além de expandir o tradicional três D (descanso, diversão e desenvolvimento) colocado por Dumazedier (1999) quanto à finalidade do lazer, ao introduzi-lo como mecanismo não apenas de reprodução do capital, mas também de produção ativa, na medida em que passa a ser visto como uma mercadoria que dinamiza o mercado e as relações dele derivadas.

O novo contexto global do capitalismo é bem exposto por Mascarenhas (2001, 2003, 2005), que destaca que no atual estágio do capital tudo é submetido à lógica venal da mercadoria, inclusive o universo da cultura, do qual fazem parte as atividades de lazer. Assim, os desdobramentos sobre a vida econômica engendrados pelas relações de produção se estendem para outras esferas, mais uma vez ficando comprovado que base e superestrutura não devem ser vistos como complexos unilaterais, mas, sim, como esfera de relações sociais. Neste sentido, Mascarenhas (2001) destaca que não apenas devemos visualizar no lazer um mecanismo de transformação social, posto que ele também porta o imobilismo em seu aparato arquitetural, principalmente nas condições atuais em que se transformou em mercolazer, parafraseando Mascarenhas (2005).

Mais do que nunca é preciso encarar o lazer como síntese de múltiplas determinações históricas. Determinações estas que atualmente o transformaram em verdadeira mercadoria, sendo as relações de troca as alavancas do processo atual de prática do lazer nesta sociedade culturalmente mundializada (cabe 
citar os Mcdonalds, a Disney, o Cirque Du Soleil, etc., tudo vira comércio e mercadoria mundial), caracterizada pela prática de atividades comuns em distintos contextos. É este mercolazer, esvaziado de conteúdos humano-genéricos, que a cada dia se propaga em uma velocidade assombrosa, elemento característico de um lazer a cada dia mais imediato, fútil e espontâneo. É a explosão divertida e a estandardização da aventura, cujo exemplo, nas palavras de Sant'Anna (1994), pode ser encontrado nos esportes radicais e californianos, que buscam se desenvolver pela promessa de prazer total, pela superação das energias e o extravasar dos limites.

Mais do que nunca o produto passa a criar um consumo do qual o consumidor não pode fugir, inventando, por conseguinte, o próprio consumidor, ou seja, mais do que nunca o produto passa determinar a ação humana, coisificada até mesmo quando tem por função a saída da esfera do mercado. Esta é uma das tristes antinomias do lazer, a citar: sua transformação em êxtase-lazer de acordo com as palavras de Mascarenhas (2005, p.205-206), que

[...] não é outra coisa senão a expressão categorial da qual nos valemos a fim de melhor poder traduzir aquela que para nós se apresenta como a forma mais desenvolvida e elaborada do mercolazer. Sua manifestação não se restringe apenas aos esportes de aventura, embora seja à imagem deste tipo de prática que habitualmente aparece colado, mas se materializa também através da compra divertida, na cultura das saídas, no passeio aos shoppings, está presente na euforia do espetáculo esportivo, nas baladas do circuito noturno, na drogadição que é a marca das raves, está nas atrações, brinquedos e divertimentos do parque temático, na violência simbólica que cerca o mundo dos jogos eletrônicos, na pirotecnia de efeitos visuais que se tornou a mercadoria cinema, na pornografia sonora patrocinada pala indústria fonográfica, no sexo pago comercializado pelas empresas especializadas no ramo da prostituição, dentre muitos outros serviços possíveis e inimagináveis. Ainda assim, constitui uma experiência altamente fragmentada e reiterativa, no interior de certa margem, mais formal, mais repetitiva e mais previsível, de conteúdo cada vez mais pobre no que diz respeito ao seu valor social e ao tipo de sociabilidade produzida. É a prática de lazer artificializada e atificializante, coisa pela qual o par valor-prazer tomou forma na sociedade involucral. 
A existência destes elementos destaca o caráter premente em pensarmos uma nova forma de lazer, não atreladas apenas a reprodução do ciclo de mais valia do capital. O lazer não pode mais ser visto como um campo que perde sua especificidade quando visualizamos nele uma fonte de ação sistemática e teleológica, pois essa recusa é a conformação do lazer a heterogeneidade alienante da vida cotidiana. Sendo assim, quando buscamos utilizar o lazer em uma perspectiva emancipatória, é necessário pensar em um lazer em estrita vinculação a emergência de uma educação libertária e crítica, enfim, que possibilite ao homem conhecer acuradamente os elementos de sua realidade para transformá-la rumo a novos caminhos que ampliem as mais diversas atividades colaborativas entre os homens. Ou seja, precisamos pensar no descompromisso compromissado, no tempo livre que é trabalhoso, árduo, uma noção temporal a ser construída. Esse é o desafio do lazer, qual seja: tornar uma prática desinteressada quanto aos interesses materiais em uma atividade altamente interessada na elevação da consciência social dos homens e na construção de um novo projeto histórico, que negue, mas supere por incorporação a sociedade capitalista e seu mercolazer ou êxtase-lazer. Neste contexto, certamente a Educação Física passa a se constituir como ferramenta mediadora a produção não apenas de um novo conhecimento para o lazer, mas, sim, de um novo lazer que não se torne escravo do cotidiano, da alienação e fetichização característica da sociedade atual, todavia, para tanto, precisa assumir efetivamente para si o papel de disciplina reflexiva e produtora de conhecimento, cuja proficuidade está justamente na íntima relação que estabelece entre teoria e prática, o cotidiano e o não cotidiano, o tempo livre do tempo livre alienado, cuja complexidade ontológica nos desafia, como pensadores comprometidos com a Educação Física, a pensarmos no futuro, objetivar o presente em estado de devir.

\section{Considerações finais}

Esperamos mediante este trabalho demonstrar o caráter dialético do lazer, fenômeno composto pela síntese de múltiplas determinações. Esfera que aliena e liberta simultaneamente, que produz e reproduz conhecimento, sendo que enquanto continuarmos a olhar para apenas uma destas esferas seremos incapazes de entender o fenômeno do lazer em sua totalidade.

$O$ referido entendimento passa certamente pela compreensão 
da nova estrutura das relações exploratórias capitalistas, caracterizadas não pela humanização e pela capacidade de produzir tempo livre, mas, sim, pela força em produzir desemprego, alienação, sofrimento, miséria, e a mercadorização do próprio trabalhador. Nesse sentido, fazse premente ressaltar as palavras de Padilha (2000, p.61), para quem

O caráter de divertimento implícito no lazer é inegável, mas não é este o problema maior quando se pensa em emancipação; é preciso ir mais longe na reflexão do contexto social, político e econômico, mesmo porque, denunciar a realidade não implica compromisso com mudança. O componente lúdico do lazer não é revolucionário por si só, ele apenas favorece o relaxamento, a recuperação de energias, e o esquecimento momentâneo de problemas pessoais ou sociais. [...] Neste sentido, as atividades lúdicas podem ser consideradas relativamente distantes dos critérios de produtividade e de utilidade social, mas elas não podem ser consideradas como atividades naturalmente enriquecedoras $\mathrm{e}$ estimuladoras da consciência. É preciso levar em consideração a heterogeneidade do nível de participação dos indivíduos nas atividades de lazer...

Assim, torna-se urgente pendermos o prato da balança para que o lazer deixe a esfera cotidiana como a única fonte de seu conteúdo e forma, ou seja, que não se cotidianize o lazer. Precisamos elevar as necessidades, os produtos, mas principalmente as fruições advindas da prática do lazer, pois apenas assim podemos pensar na atividade lúfica efetivamente como um espaço de contra-hegemonia e crítica social. Por conseguinte, é preciso entender o lazer não apenas como atividade que se ancora na reprodução do capital, mas, sim, elemento fundante da reprodução do gênero humano ao indivíduo, portanto, esfera de humanização e libertação. Enfim, carecemos pensar em novas relações entre o lazer e o trabalho, o lazer e a escola/disciplinas, pois o tempo do lazer está em contraposição ao tempo alienado, seja do trabalho ou da escola, e não a qualquer tempo. É o tempo alienado que impede ao lazer se transformar em ferramenta mediativa emancipatória, na medida em que retira dos homens a própria possibilidade de fazer história, porém, esta é uma problemática que certamente necessita de maiores aprofundamentos e estudos histórico-críticos. 


\section{Referências}

BRAMANTE, A. C. Lazer: concepções e significados. Licere, Revista do Centro de Estudos de Lazer e Recreação., vol.1 n.1 Belo Horizonte, 1998.

DE MASI, D. O ócio criativo. Lea Manzi (Trad.). 4 ed. Rio de Janeiro: Sextante, 2000.

DUMAZEDIER, J. Lazer e cultura popular. São Paulo: Perspectiva, 1976.

DUMAZEDIER, J. Valores e conteúdos culturais do lazer. São Paulo: SESC, 1980.

DUMAZEDIER, J. A revolução cultural do tempo livre. São Paulo: Studio Nobel; SESC, 1994.

DUMAZEDIER, J. Sociologia empírica do lazer. 2. ed. São Paulo: Perspectiva; SESC, 1999.

FALEIROS, M, I, L. Repensando o lazer. Perspectiva, São Paulo, n. 3, 1980.

GEBARA, A. O Tempo na Construção do Objeto de Estudo da História do Esporte, do Lazer e da Educação Física. ENCONTRO NACIONAL DE HISTÓRIA DO ESPORTE, LAZER E EDUCAÇÃO FÍSICA, 2., 1994, Ponta Grossa. Coletânea... Ponta Grossa: Universidade Estadual de Ponta Grossa, 1994. v. 1. p. 175-189. GEBARA, A. Considerações para uma história do lazer no Brasil.
In: BRUHNS, Heloísa (Org.). Introdução aos estudos do lazer. Campinas: Ed. da Unicamp, 1997. p. 61-81.

HOBSBAWM, E. Introdução.

In: MARX, K. Formações econômicas pré-capitalistas. 6 . ed. Paz e Terra: São Paulo; Rio de Janeiro, 1991. p. 13-64.

LESSA, S. A centralidade ontológica do trabalho em Lukács. Serviço Social e Sociedade, São Paulo, n.52, p. 7-22, 1996.

MARCASSA, L. A invenção do lazer: educação, cultura e tempo livre na cidade de São Paulo (1888-1935). 2002. Dissertação (Mestrado em Educação) - Faculdade de Educação, Universidade Federal de Goiás, Goiânia, 2002.

MARCELLINO, N. C. Estudos do lazer: uma introdução. $2^{\mathrm{a}}$ ed. Campinas: Autores

Associados, 2000.

MARCELLINO, N. C. Lazer e humanização. 4a. ed. Campinas: Papirus, 2001.

MARCELLINO, N. C. Lazer e educação. 10a. ed. Campinas: Papirus, 2002.

MARCELLINO, N. C. (org.). Lúdico, educação e educação física. ljuí: Ed. Unijuí, 2003.

MARX, Karl. O capital. Crítica da economia política. Livro $1, \mathrm{v}$. 1. Rio de Janeiro: Civilização Brasileira, 1971. 
MASCARENHAS, F. Lazer e o príncipe eletrônico. Licere, Revista do Centro de Estudos de Lazer e Recreação. Belo Horizonte, v.4, n.1, p.46-60, 2001.

MASCARENHAS, F. Lazer como prática de liberdade: uma proposta educativa para a juventude. Goiânia: Ed. UFG, 2003.

MASCARENHAS, Fernando. Entre o ócio e o negócio: teses acerca da anatomia do lazer. 307f. Tese (Doutorado) Faculdade de Educação Física - Universidade Estadual de Campinas, Campinas, 2005.

PADILHA, V. Tempo livre e Capitalismo: um par imperfeito. Campinas, SP: Editora Alínea, 2000.
PADILHA, Valquíria. Shopping Center: a catedral das mercadorias e do lazer reificado. 2003. Tese (Doutorado em Ciências Sociais) - Instituto de Filosofia e Ciências Humanas, Universidade Estadual de Campinas, Campinas, 2003. REQUIXA, R. Sugestões de diretrizes para uma política nacional de lazer. São Paulo: SESC, 1980.

ROLIM, L. C. Educação e lazer: a aprendizagem permanente. São Paulo: Ática, 1989.

SANT'ANNA, D. O prazer justificado: história e lazer. São Paulo: Marco zero, 1994.

Recebido: 30/agosto/2009 Aprovado: 27/setembro/2009 